\title{
Comparison of Two Low-Profile Prosthetic Retention System Interfaces: Preliminary Data of an In Vitro Study
}

\author{
Gabriele Cervino ${ }^{1}\left(\mathbb{D}\right.$, Marco Montanari ${ }^{2}$, Dario Santonocito ${ }^{3}{ }^{(\mathbb{C}}$, Fabiana Nicita ${ }^{1}$, \\ Riccardo Baldari ${ }^{4}$, Claudio De Angelis ${ }^{4}$, Gianni Storni ${ }^{4}$ and Luca Fiorillo ${ }^{1, *(D)}$ \\ 1 Department of Biomedical, Odontostomatological Sciences and Morphological and Functional Images, \\ School of Dentistry, Via Consolare Valeria 1, University of Messina, 98125 Messina, Italy; \\ gcervino@unime.it (G.C.); fabin92@hotmail.it (F.N.) \\ 2 Private Practice DDS, 40121 Bologna, Italy; montmarco@virgilio.it \\ 3 Department of Engineering, University of Messina, 98100 Messina, Italy; dsantonocito@unime.it \\ 4 Private Practice Engineer, 40121 Bologna, Italy; riccardo.baldari@rhein83.it (R.B.); \\ Claudio.deangelis@rhein83.it (C.D.A.); Gianni.storni@rhein83.it (G.S.) \\ * Correspondence: lfiorillo@unime.it
}

Received: 27 October 2019; Accepted: 21 November 2019; Published: 27 November 2019

\begin{abstract}
In recent years, a major research goal of companies has been to create mechanical components suitable for rehabilitation that are safer and more reliable. Evaluating their biomechanical features could be a way to improve them. The purpose of this study was to evaluate the different biomechanical features of low-profile retentive systems (Rhein () . Two different attachment systems were tested: OT Equator® Smart Box and Locator® R-TX. Once a machine was created for the simulation of the connection and disconnection of the attacks in a combined manner, it was possible to evaluate these parameters over time. Attachments were mounted in two different configurations of the divergence angle: $10^{\circ}$ and $50^{\circ}$. The drop retention force proved to be stable over time. The Locator $\AA$ R-TX attachment experienced a more rapid decrement of the retention force than the OT Equator $\mathbb{R}$ Smart Box. Both tested systems experienced a high drop in retention; this drop tended to stabilize after 1.5 years of use, and it was correlated with the divergence angle. The OT Equator $($ Smart Box system underwent this loss of retention more gradually than the Locator $®$ R-TX. This study demonstrates preliminary results from a bioengineering and biomechanical point of view, providing useful information for the continuous improvement of these devices and, therefore, for the quality of patients' oral health.
\end{abstract}

Keywords: dentistry; oral rehabilitation; dental implant; bioengineering; biomechanical

\section{Introduction}

\subsection{Background}

Implant-supported mandibular overdentures retained by two implants are a cost-effective treatment option for edentulous patients [1,2]. This treatment improves the stability and retention of the mandibular complete denture and patients' masticatory function compared with conventional removable dentures [2-4].

Retention of a removable denture is an important property that allows the forces of dislodgement to be resisted in a direction opposite to its path of placement $[5,6]$. Several attachment systems have been developed to improve the retention characteristics and stability of implant-supported 
overdentures, such as splinted (bar attachment) or unsplinted systems (o-ring/ball/spherical types, magnets, telescopic crowns, or stud attachments) [7].

The performance of implant-supported overdentures depends on the retentive capacity of the attachment system employed, providing forces that are strong enough to prevent overdenture displacement [8,9]. Biomechanical knowledge of different attachment systems could help clinicians to select the proper attachment for each case [10-12].

Among the attachment systems, stud attachments are widely accepted for their lower technique sensitivity, better affordability, easier repairability, and their ability to be successfully positioned on resorbed edentulous ridges $[10,13]$. Attachment system selection depends on a variety of factors that should be identified early in the treatment sequence, such as the alignments of the implants, the retention value needed, the available vertical and horizontal prosthetic space, and the jaw morphology [14,15]. Ultimately, the decision is usually based on the clinician's experience and preference $[10,11]$.

Several stud attachment systems have been developed over the years, including OT Equator ( (Rhein83, Bologna, Italy) and Locator@ R-TX (Zest Anchors Inc, Escondido, CA, USA). The OT

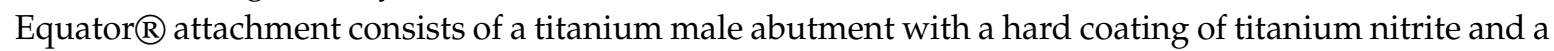
semispherical shape reminiscent of ball attachments that supports a stainless-steel retentive cap housing nylon retentive inserts available with four levels of retention encoded with a color. The OT Equator $®$ Smart Box is a container of caps with an innovative design which, thanks to a tilting mechanism with a rotation fulcrum, allows for the passive insertion of the attachment even in conditions of divergence up to $50^{\circ}$. Four types of retention caps are available: extra-soft, soft, standard, and hard.

A next-generation Locator $₫$ R-TX attachment system was recently introduced to improve the limitations associated with conventional Locator attachments. The new features include an aesthetic, harder, and more wear-resistant titanium carbon nitride coating, dual-retentive features on the external surface of the abutment, and a reduction in the coronal abutment dimension. The denture attachment housings are designed to permit a $50 \%$ increase in pivoting capability and up to a $30^{\circ}$ correction per implant as opposed to a maximum of $20^{\circ}$ correction per implant with a conventional locator. Moreover, Locator® R-TX offers one set of inserts (gray $=$ zero retention, blue $=$ low retention, pink $=$ medium retention, white $=$ high retention) with improved design to resist edge deformation.

\subsection{Aim}

This study aimed to evaluate the retention force of these two attachment systems for overdenture. In particular, the study sought to evaluate the maximum force required to remove the overdenture while comparing three types of retentive caps for each attachment system over time.

\section{Results}

During each cycle, the maximum force of the removal phase was registered, and the average value with standard deviation was estimated for the three tests. The average retention force vs. time, in years, was plotted for each of the two different classes of attachment systems.

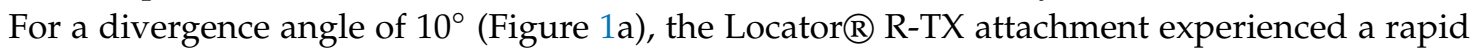
decrement of the retention force in the first half year. The value tended to stabilize after 2 years, converging, independently of the cap retention class, to a force value of $9.0 \pm 0.7 \mathrm{~N}$ (extra-soft: 8.2 $\pm 3.8 \mathrm{~N}$; soft: $9.4 \pm 1.0 \mathrm{~N}$; standard: $9.4 \pm 1.7 \mathrm{~N}$ ). The OT Equator $囚$ Smart Box attachment system experienced a more gradual change in the retention force, which tended to stabilize after 2.5 years, maintaining a different retention force for the three different cap classes (extra-soft: $7.9 \pm 1.1 \mathrm{~N}$; soft: $12.6 \pm 1.4 \mathrm{~N}$; standard: $16.8 \pm 2.5 \mathrm{~N}$ ). As reported in Figure $1 \mathrm{~b}$, after 1 year the Locator $\mathbb{R}$ R-TX system presented a dramatic drop in the retention force (extra-soft: $16.43 \%$; soft: $24.96 \%$; standard: $17.85 \%$ ), while the OT Equator@ Smart Box presented a gradual slope change in the force drop, with a final drop after 4.56 years of $62.42 \%$ (extra-soft: $69.73 \%$; soft: $59.97 \%$; standard: $57.56 \%$ ) vs. $20.17 \%$ for the Locator® R-TX attachment (extra-soft: $21.20 \%$; soft: $24.80 \%$; standard: $14.52 \%$ ). 


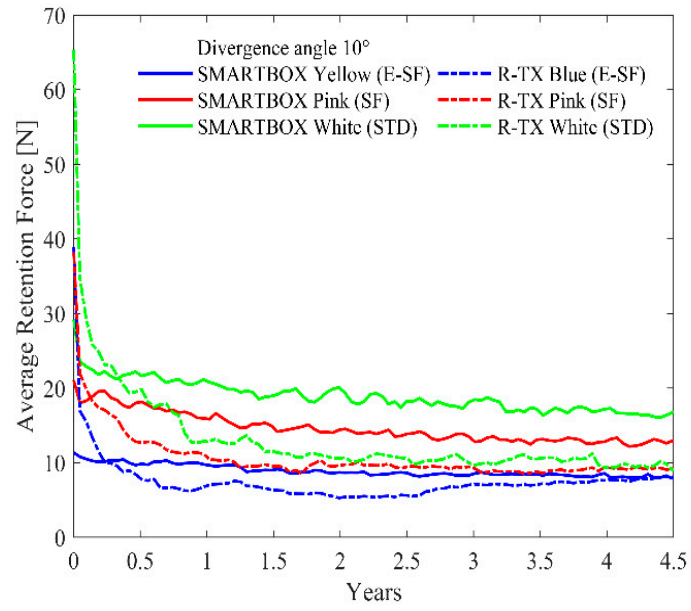

(a)

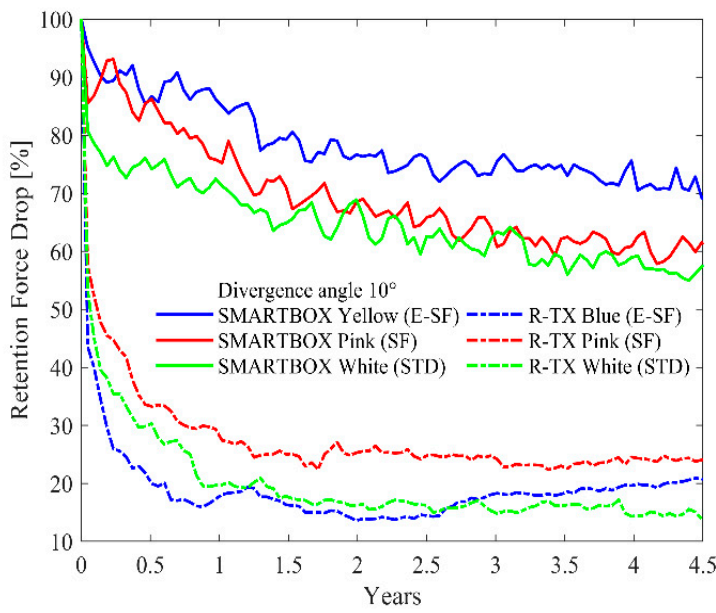

(b)

Figure 1. (a) Average retention force for a divergence angle of $10^{\circ}$; (b) Average retention force for a divergence angle of $50^{\circ}$ (1096.49 cycles for the year).

For a divergence angle configuration of $50^{\circ}$, both the attachment systems experience a force retention change during the first half year (Figure $2 a, b)$. In particular, the Locatorß R-TX attachment showed an abrupt change with a final average value of the retention force after 4.56 years of $17.5 \pm$ 1.6 N with a small difference between cap retention classes (Extra-Soft: $16.5 \pm 5.0 \mathrm{~N}$; Soft: $16.6 \pm 8.5 \mathrm{~N}$; Standard: $19.4 \pm 3.04 \mathrm{~N}$ ), but maintaining a higher retention force compared to the Smart Box system. On the other hand, the Smart Box attachment tended to stabilize to a different value of the retention force. It maintained the resistance class during the time (Extra-Soft: $6.2 \pm 0.1 \mathrm{~N}$; Soft: $11.2 \pm 0.5 \mathrm{~N}$; Standard: $19.3 \pm 0.5 \mathrm{~N})$.

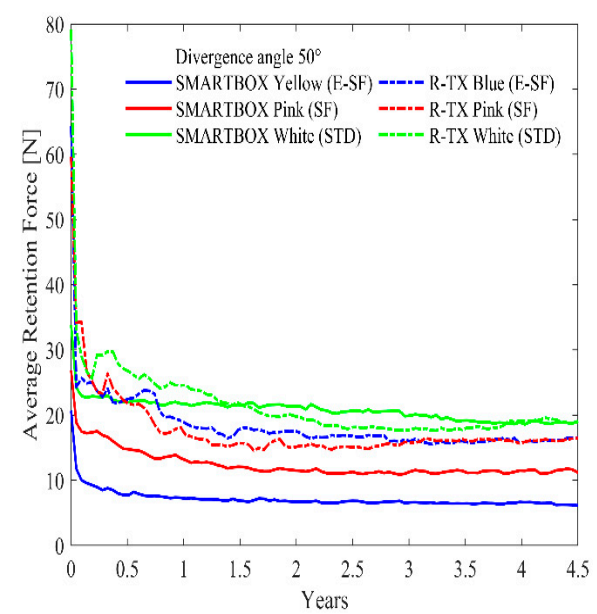

(a)

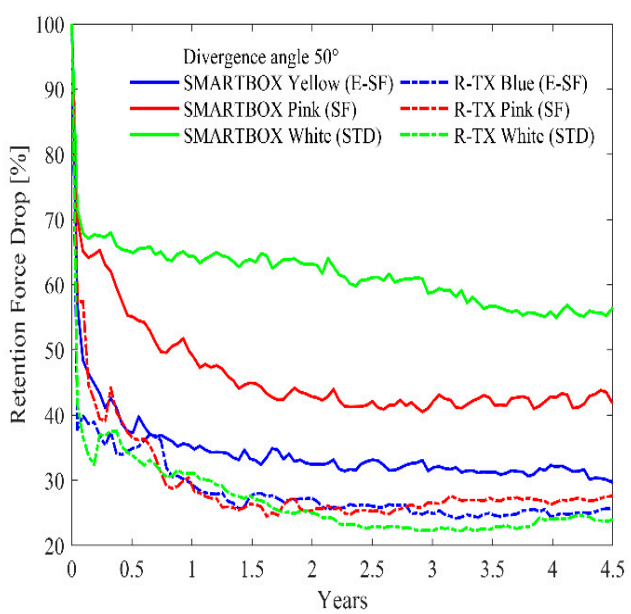

(b)

Figure 2. (a) Retention drop force for a divergence angle of $10^{\circ}$; (b) Retention drop force for a divergence angle of $50^{\circ}$ (1096.49 cycles for the year).

Both the attachments experience a high drop in the retention force, which tended to stabilize after about 1.5 years (Figure 2b). All of the Locatorß group reached up to $26.04 \%$ drop in the retention force after 4.56 years (Extra-Soft: $25.71 \%$; Soft: $27.88 \%$; Standard: $24.54 \%$ ), while the Smart Box group revealed a higher retention force drop with respect to the $10^{\circ}$ divergence angle configuration, but smaller compared to the Locator@ attachment (Extra-Soft: 30.25\%; Soft: $41.94 \%$; Standard: 57.11\%). 


\section{Discussion}

Smart Box® is an abutment container that, thanks to a tilting mechanism with a rotation fulcrum, allows passive insertion even in extreme divergences up to $50^{\circ}$. This feature allows forces passivation and, therefore, better predictability characteristics of our rehabilitation [16-18]. It does improve the quality of life of our patients, avoiding complex and invasive surgery, in many cases necessary to perform a fixed implant-prosthetic rehabilitation. This is one of the advantages of this systematic. As shown from Figure 3 in detail, the insertion of the Smartbox® also occurs with divergent angles. Other

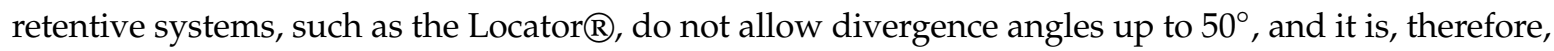
possible that residual forces are created in our prosthesis, or in the structure, or on dental implants' position. Residual forces could damage mechanical components or cause biological damages [18,19]. The Overdenture is a mobile prosthesis, on dental implants, stable and comfortable; the upper one may not have a palate plate. Many patients have difficulty keeping their removable prosthesis stable, particularly that of the jaw, or they have difficulty bearing the palate in the case of the upper arch. The dentures are removable (detachable), so they could be cleaned easily (they allow hygienic maneuvers on implants), an advantage for elderly patients with reduced mobility and with lost dexterity. At the same time, these prostheses are perfectly stable during chewing and talking. It is the simplest type of implant-prosthetic rehabilitation in which two or four dental implants are positioned in the anterior area of the jaw or the maxilla. A functional set-up is thus obtained in which the prosthesis is anchored to the implants anteriorly and rests on the mucosa $[19,20]$. From the obtained results in this simulation, the retention force is greater over time using the OTEquator $₫$ rather than the other systematics, especially in the case where there is disparallelism between dental implants. The drop of retention force is higher on the Locator $囚$, and this gives a lower guarantee of duration over time and the worst predictability of oral rehabilitation. Certainly, it should be considered that this is a simulation, and the insertion and disconnection cycles have been tested in a short period that could somehow alter both the internal nylon inserts and the metal boxes themselves.

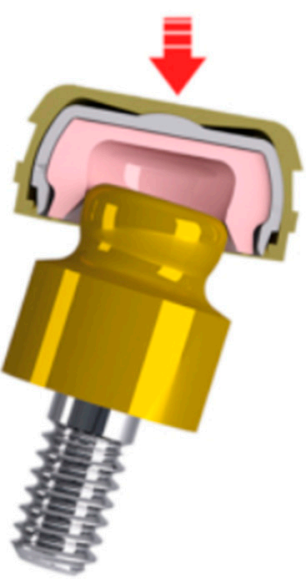

A

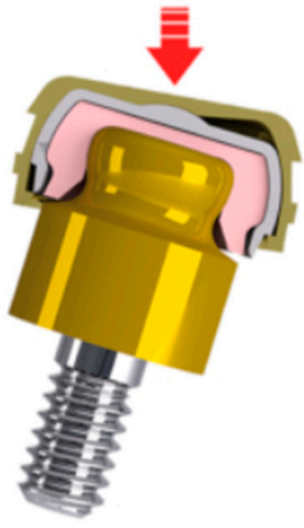

B

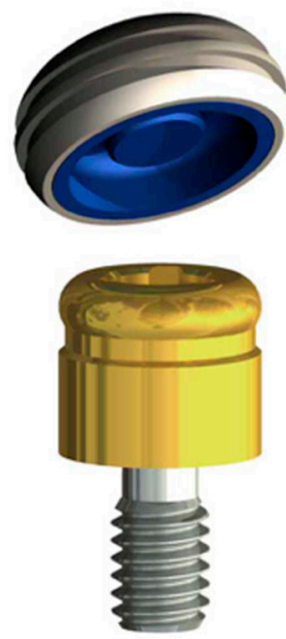

\section{Materials and Methods}

Two different attachment systems with three different classes of retentive caps were tested: OT

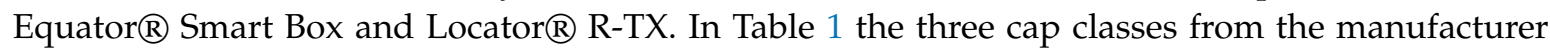
adopted for each of the two attachment systems with the respective nominal retention force are reported [21,22]. 
Table 1. Cap classes for the attachment systems.

\begin{tabular}{ccc}
\hline Cap Class & OT EQUATOR® SMART BOX & LOCATOR® R-TX \\
\hline Extra-Soft (E-SF) & Yellow $(0.60 \mathrm{~kg})$ & Blue $(0.68 \mathrm{Kg})$ \\
\hline Soft $(\mathrm{SF})$ & Pink $(1.20 \mathrm{~kg})$ & Pink $(1.36 \mathrm{~kg})$ \\
\hline Standard (STD) & White $(1.80 \mathrm{~kg})$ & White $(2.27 \mathrm{~kg})$ \\
\hline
\end{tabular}

The tests simulate the insertion-removal cycle of the overdenture from the attachment system evaluating the maximum force needed to detach the implant overdenture from the attachment system. Two implant replicas Core-Vent, diameter $3 \mathrm{~mm}$ with internal hexagon, were fixed into a dedicated specimen with auto polymerizing PMMA resin (DuraLay, GC Pattern Resin) to simulate the elastic mobility behavior of the osteointegrated implant (Figure 4a).

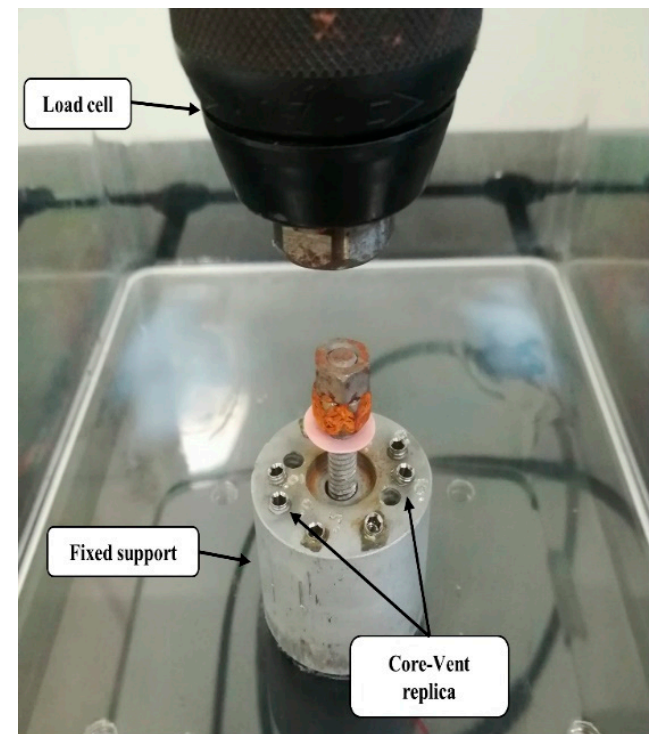

(a)

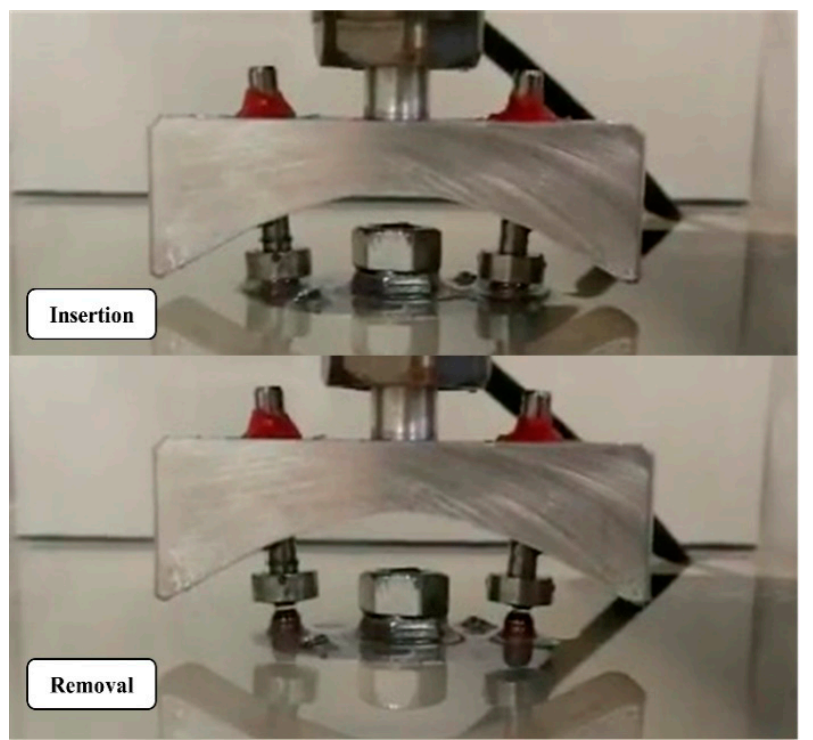

(b)

Figure 4. (a) Testing setup; (b) Insertion and removal phase during one test cycle.

The tested attachment systems (patrix) were screwed onto the implant replicas according to the instructions of the manufacturers. The OT Equator $\AA$ and the Locator $($ R-TX were screwed with a torque in the range of 22 to $25 \mathrm{Ncm}$, adopting, respectively, the OT Equator $($ screwdriver (Rhein83) and the Locator $®$ screwdriver (Zest). Afterward, the female components were incorporated into the notched surface of the matrix mounting, with the two components already connected, adopting a direct pick-up technique. Finally, the matrix mounting was connected to the load cell of an electrodynamic tensile testing machine MTS Acumen 807.001 (MTS headquarters, Eden Prairie, MN, USA) with a load cell of $1.5 \mathrm{kN}$ (Figure $4 \mathrm{~b}$ ). The testing machine was adopted to induce a vertical uniaxial dislodging force to the attachment system, simulating actual clinical situations. Each retentive cap was subjected to 5000 insertion-separation cycles, assuming 4.56 years of removing and inserting the overdenture three times a day [21,22], this means that there are 1096.49 insertion cycles for a year. The cycle routine consists of $2.5 \mathrm{~mm}$ upwards in 2.5 seconds, 0.1 seconds of stop, and $2.5 \mathrm{~mm}$ downwards in 2.5 seconds with 1.5 seconds of connection on the attachment to allow the elastic recovery of the attachment components [23]. During the test, artificial saliva, Sinopia, was used as a lubricant at a constant temperature of $37^{\circ} \mathrm{C}$, simulating potential normal conditions of the oral cavity.

A couple of attachments for each of the two adopted systems were mounted in two different configurations of divergence angle: the former with an angle of $10^{\circ}\left(-5^{\circ} /+5^{\circ}\right.$ from the main axis), the 
latter with an angle of $50^{\circ}\left(-25^{\circ} /+25^{\circ}\right.$ from the main axis). For each cap, three tests were performed, for a total number of twelve tests per divergence angle configuration.

\section{Conclusions}

The obtained results from this in vitro study could provide useful information for the performance improvement of retentive systems. Already the discrepancy of results in favor of the Equator system is a good starting point to understand what is the ideal morphology for a retentive system with higher retention force over time.

Author Contributions: Conceptualization, M.M., R.B., C.D.A., and G.S.; methodology, D.S., R.B., C.D.A., and G.S.; software, D.S., R.B., C.D.A., and G.S.; validation, D.S., R.B., C.D.A., and G.S.; data curation, D.S., R.B., C.D.A., and G.S.; writing-original draft preparation, D.S. and L.F.; writing-review and editing, L.F. and F.N.; supervision, G.C. and L.F.; project administration, G.C.

Funding: This research received no external funding.

Conflicts of Interest: The authors declare no conflict of interest.

\section{References}

1. Feine, J.S.; E Carlsson, G.; A Awad, M.; Chehade, A.; Duncan, W.J.; Gizani, S.; Head, T.; Heydecke, G.; Lund, J.P.; MacEntee, M.; et al. The McGill consensus statement on overdentures. Mandibular two-implant overdentures as first choice standard of care for edentulous patients. Gerodontology 2002, 19, 601-602.

2. Awad, M.A.; Rashid, F.; Feine, J.S. The effect of mandibular 2-implant overdentures on oral health-related quality of life: An international multi centre study. Clin. Oral Implants Res. 2014, 25, 46-51. [CrossRef] [PubMed]

3. Sadowsky, S.J. Mandibular implant-retained overdentures: A literature review. J. Prosthet. Dent. 2001, 86, 468-473. [CrossRef] [PubMed]

4. Bakke, M.; Holm, B.; Gotfredsen, K. Masticatory function and patient satisfaction with implant-supported mandibular overdentures: A prospective 5-year study. Int. J. Prosthodont. 2002, 15, 575-581. [PubMed]

5. The Glossary of Prosthodontic Terms. J. Prosthet. Dent. 2005, 94, 10-92. [CrossRef] [PubMed]

6. Cune, M.; Van Kampen, F.; Van Der Bilt, A.; Bosman, F. Patient satisfaction and preference with magnet, bar-clip, and ball-socket retained mandibular implant overdentures: A cross-over clinical trial. J. Prosthet. Dent. 2005, 94, 471. [CrossRef]

7. Kobayashi, M.; Srinivasan, M.; Ammann, P.; Perriard, J.; Ohkubo, C.; Muller, F.; Belser, U.C.; Schimmel, M. Effects of in vitro cyclic dislodging on retentive force and removal torque of three overdenture attachment systems. Clin. Oral Implants Res. 2014, 25, 426-434. [CrossRef]

8. Rutkunas, V.; Mizutani, H.; Takahashi, H.; Iwasaki, N. Wear simulation effects on overdenture stud attachments. Dent. Mater. J. 2011, 30, 845-853. [CrossRef]

9. Srinivasan, M.; Schimmel, M.; Badoud, I.; Ammann, P.; Herrmann, F.R.; Muller, F. Influence of implant angulation and cyclic dislodging on the retentive force of two different overdenture attachments - an in vitro study. Clin. Oral Implants Res. 2016, 27, 604-611. [CrossRef]

10. Alsabeeha, N.H.; Payne, A.G.; Swain, M.V. Attachment systems for mandibular two-implant overdentures: A review of in vitro investigations on retention and wear features. Int. J. Prosthodont. 2009, 22, 429-440.

11. Kim, H.-Y.; Lee, J.-Y.; Shin, S.-W.; Bryant, S.R. Attachment systems for mandibular implant overdentures: A systematic review. J. Adv. Prosthodont. 2012, 4, 197-203. [CrossRef] [PubMed]

12. Prasad, D.; Prasad, D.; Buch, M. Selection of attachment systems in fabricating an implant supported overdenture. J. Dent. Implant. 2014, 4, 176. [CrossRef]

13. Naert, I.; Alsaadi, G.; Quirynen, M. Prosthetic aspects and patient satisfaction with two-implant-retained mandibular overdentures: A 10-year randomized clinical study. Int. J. Prosthodont. 2004, 17, 401-410. [CrossRef] [PubMed]

14. Sadowsky, S.J.; Caputo, A.A. Effect of anchorage systems and extension base contact on load transfer with mandibular implant-retained overdentures. J. Prosthet. Dent. 2000, 84, 327-334. [CrossRef] [PubMed]

15. Evtimovska, E.; Masri, R.; Driscoll, C.F.; Romberg, E. The Change in Retentive Values of Locator Attachments and Hader Clips over Time. J. Prosthodont. 2009, 18, 479-483. [CrossRef] 
16. Bramanti, E.; Cervino, G.; Lauritano, F.; Fiorillo, L.; D’Amico, C.; Sambataro, S.; Denaro, D.; Famà, F.; Ierardo, G.; Polimeni, A.; et al. FEM and Von Mises Analysis on Prosthetic Crowns Structural Elements: Evaluation of Different Applied Materials. Sci. World J. 2017, 2017, 1-7. [CrossRef]

17. Bramanti, E. Oral health-related quality of life in partially edentulous patients before and after implant therapy: A 2-year longitudinal study. Oral Implant. 2013, 6, 37-42. [CrossRef]

18. Cicciù, M.; Beretta, M.; Risitano, G.; Maiorana, C. Cemented-retained vs screw-retained implant restorations: An investigation on 1939 dental implants. Minerva Stomatol. 2008, 57, 167-179.

19. Stefano, D.; De Stefano, R. Psychological Factors in Dental Patient Care: Odontophobia. Medicina 2019, 55, 678. [CrossRef]

20. Germano, F.; Bramanti, E.; Arcuri, C.; Cecchetti, F.; Cicciù, M. Atomic force microscopy of bacteria from periodontal subgingival biofilm: Preliminary study results. Eur. J. Dent. 2013, 7, 152-158. [CrossRef]

21. Wichmann, M.G.; Kuntze, W. Wear behavior of precision attachments. Int. J. Prosthodont. 1999, 12, $409-414$. [PubMed]

22. Besimo, C.E.; Guarneri, A. In vitro retention force changes of prefabricated attachments for overdentures. J. Oral Rehabilitation 2003, 30, 671-678. [CrossRef] [PubMed]

23. Chaves, C.; De Souza, R.; Cunha, T.; Vecchia, M.; Ribeiro, A.; Bruniera, J.; Silva-Sousa, Y. Preliminary In Vitro Study on O-Ring Wear in Mini-Implant-Retained Overdentures. Int. J. Prosthodont. 2016, 29, 357-359. [CrossRef] [PubMed]

(C) 2019 by the authors. Licensee MDPI, Basel, Switzerland. This article is an open access article distributed under the terms and conditions of the Creative Commons Attribution (CC BY) license (http://creativecommons.org/licenses/by/4.0/). 